American Journal of Pharmaceutical Education 2019; 83 (6) Article 7195.

\title{
COMMENTARY
}

\section{Prospective Health Professions Students' Misperceptions About Pharmacists}

\author{
Erin Hickey, PharmD, ${ }^{a}$ Joseph DiPiro, PharmD, ${ }^{\mathrm{b}}$ Frank Romanelli, PharmD ${ }^{\mathrm{a}, \mathrm{c}, \mathrm{d}}$ \\ ${ }^{a}$ Department of Pharmacy, University of Kentucky HealthCare, Lexington, Kentucky \\ ${ }^{\mathrm{b}}$ School of Pharmacy, Virginia Commonwealth University, Richmond, Virginia \\ ${ }^{c}$ College of Pharmacy, University of Kentucky, Lexington, Kentucky \\ ${ }^{\mathrm{d}}$ Executive Associate Editor, American Journal of Pharmaceutical Education, Arlington, Virginia \\ Submitted June 5, 2018; accepted March 5, 2019; published August 2019.
}

\begin{abstract}
Public misperceptions about the pharmacy profession have the potential to impact pharmacy education, practice, and the health of those who pharmacists serve. Student misperceptions of the profession can lead to fewer applicants to pharmacy schools and frustration among pharmacy students and faculty members. With the recent decline in applicants to Doctor of Pharmacy (PharmD) programs, professional pharmacy organizations, colleges and schools of pharmacy, and individual pharmacists must implement strategies that mitigate these misperceptions. This commentary discusses the potential impact of prospective health students' (ie, students pursuing admission to health professional programs) misperceptions on the supply of quality candidates to PharmD programs. Strategies to elevate the image of the profession at the individual and collegiate level are discussed.
\end{abstract}

Keywords: prospective health students, misperception, admissions

Many pharmacists will remember how it feels to share with someone that they are a pharmacist or student pharmacist and receive uninformed replies. Most people are not aware of the broad scope of pharmacists' responsibilities or the variety of pharmacy practice settings. Most would have a difficult time envisioning a pharmacist who was not involved with the physical handling of medications. Even some colleagues in other health professions fail to recognize or appreciate the level of education and magnitude of training required to practice pharmacy today.

While objectively capturing the public perception of pharmacists on a large scale is difficult, the representation of pharmacists in the media has primarily been negative, with pharmacists largely portrayed as victims or villains. ${ }^{1}$ Rosenthal and colleagues' 2011 survey of 100 community pharmacists in Canada found that participants viewed themselves primarily as "dispensers of medication" rather than patient-centered practitioners. ${ }^{2}$ Ongoing negative media portrayals of pharmacists and a lack of progress in elevating awareness have contributed to misperceptions about the professional role of pharmacists.

An underdeveloped public understanding of the profession may not seem of paramount importance or urgency. However, the general public represents, among

Corresponding Author: Erin Hickey, University of Kentucky HealthCare, 800 Rose St., Rm. H110, Lexington, KY 40536. Tel: 804-482-9831. E-mail:ehickey@vcu.edu other things, patients who determine through trust and expectation how engaged a pharmacist can be. Also, misunderstanding of the profession may cause other healthcare professionals to not engage in collaborative practice agreements or legislators to not see the importance of increasing accessibility and reimbursement mechanisms for pharmacists. Finally, the general public includes prospective pharmacy students and the people in their lives who influence their career choice. Just as public misperceptions have the potential to impact pharmacy practice, misperceptions of pharmacists among prospective health students may result in insufficient numbers of quality applicants to PharmD programs. This is a particularly timely issue given recent declines in the pharmacy applicant pool.

Applications to PharmD programs have been in steady decline since 2012. Around this time period, anecdotal reports of a contracting job market began to surface. However, the 2014 National Pharmacist Workforce Survey reported a balance of supply of and demand for pharmacists in the job market. Furthermore, in the fourth quarter of 2017, the Pharmacist Demand Index (PDI) ranged from 2.88 to 3.22 , on a scale where a score of three signifies that demand is in balance with supply. ${ }^{3,4}$ Nevertheless, applicants to PharmD programs decreased from 17,630 in $2012-2013$ to 13,728 in $2017-2018 .^{5}$ Conversely, medical, nursing, and physician assistant training programs have not experienced a similar decline. In fact, the number of applicants to US medical schools has 


\section{American Journal of Pharmaceutical Education 2019; 83 (6) Article 7195.}

increased by at least 1,000 since $2010 .^{6}$ The National League of Nursing reports that $64 \%$ of bachelor of science in nursing programs turned down qualified applicants from 2010 to 2014 . $^{7}$ Likewise, physician assistant programs experienced a $10.7 \%$ increase in total applications submitted from 2014 to $2017 .{ }^{8}$ Each profession undoubtedly has its own stereotypes and public perception challenges. Nevertheless, the profession of pharmacy is experiencing an expansion of opportunities and nontraditional roles, including but not limited to involvement in precision medicine, specialty pharmacy, public health, and leadership. Evidence demonstrates growth of pharmacy practice settings and a balance of job supply and demand, yet applicant interest is declining.

Medicine, dentistry, pharmacy, and physical therapy all require a strong science knowledge base and solid communication skills. The ideal prospective student for most health professions is, in most cases, similar. Most of these students have taken similar prerequisite coursework and are interested in becoming a medical professional because they want to use their science knowledge to help people. Practitioners in each of these fields certainly have the potential to impact societal health. However, not all health professions are universally understood, and some are more publicly respected than others. Multidisciplinary evidence from students actively pursuing admission to medicine, dentistry, pharmacy, and physical therapy programs suggests an appreciation for the pharmacist's role on the health care team, yet a poor understanding of the pharmacists' corresponding responsibilities and practice settings. ${ }^{9}$ This raises a few questions: Are prospective health students less likely to apply to pharmacy school because the public image of pharmacists is unknown or misunderstood? Do prospective health students who may be better suited for a career in pharmacy apply to other professional programs? Finally, do pre-pharmacy students apply to pharmacy school with misperceptions about the profession? If the answer to any of these questions is yes, then there is an opportunity for improvement as a profession.

Though factors beyond the control of school administrators and faculty members may contribute to a student's ultimate career path, the loss of potential pharmacy school applicants may be related to a misunderstanding of what it means to be a pharmacist. High-performing students may be lost to other health professions programs for various reasons. Also, pharmacy schools may gain students who pursue the profession based on misleading media portrayals of what it means to be a pharmacist or on misperceptions stemming from a single experience, such as shadowing a pharmacist. A student who shadows a pharmacist in a setting where the pharmacist has little patient contact and communication may be left with the impression that a career in pharmacy would not necessarily require them to interact with patients. However, they would be failing to realize the importance of a pharmacist being able to effectively communicate medical information to patients as well as other health professionals. Given that the PharmD curricula heavily emphasizes communication skills, this misperception may result in the student struggling to complete the PharmD program.

While the composition of the applicant pool has an obvious impact on the future of the profession, it may also impact the faculty and student experience upon matriculation. As curricula evolve to meet new standards, students with misperceptions of the pharmacy profession may become frustrated at the prospect of facing rigorous courses and co-curricular activities. Applicants who have not been properly informed about their future professional roles, such as the student mentioned above, may quickly become disillusioned with a curriculum designed to emphasize the provision of direct patient care. This phenomenon unfolded in the early 1990s when many colleges and schools of pharmacy began instruction related to pharmacy-based delivery of immunizations and physical assessment. ${ }^{10-12}$ At that time, anecdotal reports of student resistance to this new teaching surfaced. Learners at that time purported that pharmacy-based immunizations and physical assessment instruction were inconsistent with their perceptions of pharmacy practice. Students' frustration with perceived mismatches between education and practice could influence their motivation for academic success as well as their evaluations of courses and faculty members. Collaterally, faculty frustration with disengaged and resistant students certainly influences the morale at schools and colleges of pharmacy.

Explaining the profession to those outside of pharmacy is challenging. We can and should work collectively at the personal, collegiate, and professional organization levels to raise the profile of pharmacy as an essential health profession, as stated in priority 1 of the American Association of Colleges of Pharmacy (AACP) strategic plan. ${ }^{13}$ By focusing on prospective health students, pharmacists can improve the applicant pool and in turn generate graduates of PharmD programs who are more informed advocates of the profession. This focus can include capitalizing on educational resources and opportunities, supporting prospective health advisors, and instituting the most informative admissions and interview processes.

Pharmacy Is Right for Me is a collaborative, national, web-based platform highlighting opportunities in pharmacy with the intention of raising awareness of the 


\section{American Journal of Pharmaceutical Education 2019; 83 (6) Article 7195.}

profession among students, parents, and educators. ${ }^{14}$ Pharmacy schools can use this resource and similarly helpful resources, such as the American Pharmacists Association (APhA) Career Pathways Tool, to take action to dispel any misperceptions prospective students may have about pharmacy. Potential settings in which to use these resources include career days, student health club meetings, and pre-health science classes. Although interprofessional education (IPE), including introduction to professional roles and responsibilities, is now embedded within most pharmacy and other health professions training, some IPE topics lend themselves well to inclusion within pre-health science courses. ${ }^{15}$ Pre-health science courses that demonstrate and clarify the image of the pharmacist can both enrich interprofessional knowledge and inform prospective health student career decisions. For example, Virginia Commonwealth University School of Pharmacy participates in a six-week prospective health student pipeline program with multiple health-professional schools in which prospective students complete IPE. ${ }^{16}$ While targeting middle and high school students is beneficial, if schools do not focus on recruiting more advanced prospective health professions students, the profession will miss out on a population for which career decision-making is both immediately relevant and adaptable.

Health professions advisors, including pre-pharmacy advisors, are invaluable for informing students about the profession. Pre-health advisors are often the first point-of-contact a prospective health student has with their future profession. A well-informed pre-health advisor with a positive perception of the pharmacy profession and its associated curricula and training programs can have significant influence on students. Informed advisors may also be in the best position to effectively identify those students best suited for pharmacy. Therefore, educating pre-pharmacy advisors should be a top priority for admissions and engagement offices. The development of relationships with pre-pharmacy and pre-health science advisors regionally gives pharmacy schools a mechanism to elevate the image of pharmacists through a top-down approach, and can also lead to opportunities for schools and colleges of pharmacy to employ relational recruiting strategies in which pre-health students are longitudinally and meaningfully engaged.

Informative interview processes are another important way for colleges and schools to recruit a sufficient quality and quantity of applicants. In order to identify and clarify pre-pharmacy student misperceptions, these interview processes should inform the schools of not only the student's soft skills and professional abilities, but also their knowledge and understanding of pharmacist roles. It is just as important that the interview process serve as an opportunity for education and an avenue for elevating the image of pharmacists. An effective interview process, in this regard, is mutually beneficial for the institution and the prospective student.

Finally, all pharmacists have the potential to influence prospective pharmacy students on a daily basis as they interact with friends, neighbors, and even strangers while going about their professional and personal lives. Any encounter with the public in which a pharmacist shares their profession is an opportunity to elevate the profession. Providing a friendly but informative reply to an offhand question like, "So how long have you been pushing pills?" can be an opportunity to educate the general public about the pharmacy profession. That chance encounter and conversation with a pharmacist while shopping or attending a ballgame may be just the impetus a student needs to pursue a career in pharmacy.

\section{REFERENCES}

1. Yanicak A, Mohorn PL, Monterroyo P, Furgiuele G, Waddington L, Bookstaver PB. Public perception of pharmacists: film and television portrayals from 1970 to 2013. J Am Pharm Assoc. 2015;55(6):580-586.

2. Rosenthal MM, Breault RR, Austin Z, Tsuyuki RT. Pharmacists self-perception of their professional role: insights into community pharmacy culture. J Am Pharm Assoc. 2011;51(3):363-367.

3. Pharmacist Demand Indicator. https://pharmacymanpower.com/. Accessed March 16, 2018.

4. Final Report of the 2014 National Sample Survey of the Pharmacist Workforce to Determine Contemporary Demographic Practice Characteristics and Quality of Work-Life. Midwest Pharmacy Workforce Research Consortium. https:/www.aacp.org/sites/default/ files/finalreportofthenationalpharmacistworkforcestudy2014.pdf. Accessed March 8, 2018.

5. March 3, 2018 PharmCAS Volume Update. American Association of Colleges of Pharmacy. Accessed Apr 28, 2018. https:// higherlogicdownload.s3-external-1.amazonaws.com/AACP/June \% 2021\%202019\%20Volume\%20Update2.pdf?AWSAccessKeyId= AKIAJH5D4I4FWRALBOUA\&Expires $=1564881033 \&$ Signature $=$ Q5UQSCsJJ0PUp\%2F9jKrpnScZzfP4\%3D.

6. Association of American Medical Colleges. Table A-1: U.S. Medical School Applications and Matriculants by School, State of Legal Residence, and Sex, 2017-2018. https://www.aamc.org/ download/321460/data/factstablea3.pdf. Accessed February 26, 2018. 7. 2014 National League of Nursing Biennial Survey. National League of Nursing. http://www.nln.org/docs/default-source/ newsroom/nursing-education-statistics/percentage-of-programs-thatturned-away-qualified-applicants-by-program-type-2012-and-2014(pdf).pdf?sfvrsn=0. Accessed March 4, 2018.

8. 2015-2017 Cycles Applicant Comparison Report. Central Application Service for Physician Assistants. http://paeaonline.org/ caspa/program-resources/. Accessed March 8, 2018.

9. Hickey EL, Dumke EK, Brown BE, Ballentine RL. Prospective health students' perceptions of the pharmacist role in the interprofessional team. J Interprof Care. 2018;32(2):250-253. 10. Prescott WA, Bernhardi C. Immunization education in US pharmacy colleges and schools. Am J Pharm Educ. In Press. Nov 6 


\section{American Journal of Pharmaceutical Education 2019; 83 (6) Article 7195.}

2017. https://www.ajpe.org/doi/pdf/10.5688/ajpe6765. Accessed March 4, 2018.

11. Kamal KM, Madhavan SS, Maine LL. Impact of the American Pharmacists Association's (APhA) immunization training certification program. Am J Pharm Educ. 2003;67(4):1-10.

12. Bolesta S. Trombetta DP, Longyhore DS. Pharmacist instruction of physical assessment for pharmacy students. Am J Pharm Educ. 2011;75(2):1-10

13. American Association of Colleges of Pharmacy Strategic Plan 2016-2019. American Association of Colleges of Pharmacy. https:// www.aacp.org/sites/default/files/2017-11/strategicplan-Sept17.pdf. Accessed March 8, 2018.
14. Pharmacy is Right for Me. http://pharmacyforme.org. Accessed March 11, 2018.

15. Core competencies for interprofessional collaborative practice: 2016 update. Interprofessional Education Collaborative. https://www.unthsc.edu/interprofessional-education/wpcontent/uploads/sites/33/Core-Competencies-forInterprofessional-Collaborative-Practice.pdf Accessed February 28, 2018.

16. Virginia Commonwealth University Division for Health Sciences Diversity. Summer Academic Enrichment Program. https:// dhsd.vcu.edu/programs/college/summer-academic-enrichmentprogram-saep/. Accessed April 29, 2018. 